УДК: 336

DOI 10.18413/2687-0932-2020-47-2-338-353

\title{
ОСОБЕННОСТИ РАСЧЕТА СТОИМОСТИ КАПИТАЛА В КОНЦЕПЦИИ ЗЕЛЕНЫХ ФИНАНСОВ И ЗЕЛЕНЫХ ИНВЕСТИЦИЙ
}

\section{COST OF CAPITAL CALCULATION FEATURES IN THE CONCEPT OF GREEN FINANCE AND GREEN INVESTMENTS}

\author{
М.Л. Дорофеев \\ M.L. Dorofeev \\ Федеральное государственное бюджетное образовательное учреждение высшего образования \\ «Финансовый университет при Правительстве Российской Федерации», \\ Россия, 125993 (ГСП-3), г. Москва, Ленинградский просп., 49 \\ Financial University under the Government of the Russian Federation, \\ 49 Leningradsky Prospekt, Moscow, 125993, GSP-3, Russia \\ E-mail: dorofeevml@yandex.ru
}

\begin{abstract}
Аннотация
В работе проведен анализ и классификация зеленых финансов и смежных понятий, рассмотрены актуальные проблемы и сдерживающие факторы развития зеленой экономики, а также основные механизмы финансирования зеленых инвестиционных проектов. Объектом исследования является стоимость капитала для зеленых инвестиционных проектов. В работе показаны взаимосвязи между сферами базовых категорий финансов зеленой экономики, а также дана классификация содержащихся в сферах этих категорий терминологических кластеров. Кроме этого, показаны основные тенденции и ключевые проблемы, сдерживающие развитие зеленой энергетики, в мире и в РФ. Основная часть исследования посвящена вопросам определения премии (дисконта) для инвестора в зеленые финансовые инструменты фондового рынка (акции и облигации). Индикаторы рынка акций и облигаций показали, что рынок достаточно эффективен и инвесторами в первую очередь движут классические мотивации риска и доходности, а не флажок зеленой корпорации или зеленого финансового инструмента. При всей популярности концепции зеленого инвестирования мы не нашли достаточно убедительные и однозначные доказательства тому, что зеленые инвесторы платят дополнительную премию или получают дисконт при покупке зеленой акции или зеленой облигации. Вместе с тем в процессе исследования мы встретили ряд противоречий и сложностей (в основном касающихся данных для исследования), поэтому данная проблематика остается актуальной и заслуживает дальнейших исследований.
\end{abstract}

\footnotetext{
Abstract

The analysis and classification of green finance and related concepts were carried out. Current problems and constraints of green economy development, as well as the main mechanisms of financing green investment projects were considered as well. The object of this research is the cost of capital for green investment projects. The work shows the relationships between the spheres of basic categories of finance of the green economy, as well as the classification of terminology clusters contained in the spheres of these categories. In addition, we analyzed main trends and key problems impeding the development of green energy in the world and in the Russian Federation. The second and the main part of this research is devoted to the issues of determining the premium (discount) for the investor in green financial instruments of the stock market (shares and bonds). Stock and bond market indicators have shown that the market is quite efficient, and investors are primarily driven by classic risk and yield motivations rather than the green corporation or green financial instrument flag. In spite all the popularity of the green investment concept, we have not found enough convincing and unambiguous evidence that green investors pay an additional premium or receive a discount when buying a green stock or green bond. At the same time, we faced with a few contradictions and difficulties (basically connected with data for the research) when analyzing the cost of green capital, that's why this topic remains relevant and requires further development.
} 
Ключевые слова: зеленые финансы, социальные финансы, финансы устойчивого развития, зеленые облигации, зеленые инвестиции.

Keywords: green finance, social finance, sustainable development finance, green bonds, green investments.

\section{Введение}

Трансформация парадигмы энергетического обеспечения мировой экономики совершенно точно была запущена и продолжает ускоряться по мере поступления новых сигналов в динамике климатического баланса планеты Земля. Экологи и специалисты в области анализа климатической динамики указывают на повышающиеся риски, связанные с глобальным потеплением, угрожающие островным и полуостровным государствам [Arnell, et al, 2019; Eckstein, 2020]. Безусловно, такая динамика стимулирует мировую общественность реагировать, однако не все до конца осознают риски данной проблемы. В свою очередь, для холодных стран глобальное потепление, наоборот, может стать большим конкурентным преимуществом и изменить их роль в мировой экономике и мировом разделении труда. К примеру, Россия, обладая огромной территорией и в среднем холодным климатом, может получить огромные преимущества в ряде отраслей народного хозяйства в случае повышения средней температуры на планете и повышения уровня мирового океана.

В сфере научных исследований, посвященных вопросам глобального изменения климата и глобального потепления, существуют две точки зрения на заметные повышения средней температуры на планете Земля. Ряд ученых утверждают, что причиной этому явлению является перенаселенность планеты и негативное воздействие вредных для экологии планеты выбросов углекислого газа как продукта жизнедеятельности человека и общественного воспроизводства (в широком смысле этого понятия). Таким образом, развитие низкоуглеродных видов энергии позволит минимизировать этот негативный эффект, что в принципе и является одним из стимулов развития зеленой экономики в настоящее время.

Другая группа ученых утверждает, что проблема и угрозы глобального потепления миф, увеличение температуры на планете связано с долгосрочными температурными циклами и является естественным ходом событий. Тем не менее снижение зависимости от нефти, газа и угля и проведение политики энергетической диверсификации [Hamilton, 1983; Barsky and Kilian, 2004; Taghizadeh-Hesary et al., 2013, 2016; Taghizadeh-Hesary and Yoshino, 2016] - это еще один не менее важный мотив для развития зеленой экономики и зеленых финансов. Смягчение финансовой политики для развития доли зеленой экономики в мире является наиболее важным вызовом и ключевым фактором успеха достижения этой цели.

\section{Объект и методы исследования}

Понятие зеленых финансов сегодня появляется все чаще в русскоязычных СМИ и научной литературе и в основном фигурирует в контексте инвестиционных проектов и моделей экономического роста, предполагающих внедрение новых сберегающих технологий, зеленых финансовых продуктов, развития новых рынков альтернативной энергетики и видов зеленой энергии.

В работе проведен аналитический обзор различных терминов, понятий и их особенностей в рамках сравнительно новой для РФ концепции зеленых финансов. Эта работа проводилась на основе актуальной зарубежной научной литературы и эмпирических исследований, а также статистического сборника корпорации BP [BP Statistical Review of World Energy, 2019]. Целью первой части данной статьи является систематизация и классификация ключевых понятий в области зеленых финансов в контексте развития зеленой экономики.

Далее объектом исследования выступает стоимость капитала, характерная для зеленых инвестиционных проектов. Проводится анализ и систематизация различных эмпирических исследований, посвященных оценке зеленой премии / дисконта. На основе этого исследования мы предлагаем модификации общепринятых подходов оценки стоимости различных источников финансирования зеленых проектов. 


\section{Результаты и их обсуждение}

\section{Понятие и классификация зеленых финансов}

Исследование ООН [Официальный сайт ООН, 2020] в области защиты окружающей среды показывает, что данное понятие во многих странах не закреплено и не устоялось, при этом в связи с растущим рынком зеленых инвестиций и международным распространением принципов зеленых инвестиций, все больше используется в сфере государственных финансов и в деловом обороте.

Разные страны сходятся в определении общих понятий зеленых финансов, к примеру, есть полное взаимопонимание в взаимосвязях и взаимозависимостях между категориями, низкоуглеродных финансов, зеленых финансов, устойчивых финансов, климатических финансов. Понятия «устойчивые финансы» или «финансы устойчивого развития» являются наиболее широкими в этой области по мнению всех стран и включают в себя социальные, экологические, климатические, экономические, управленческие и прочие категории, которые имеют отношение к зеленой экономике. Тем не менее те же исследования показали ряд значительных терминологических расхождений в формулировках частных категорий и понятий, например, в области описания зеленой инфраструктуры.

На основе исследованного материала можно представить общие взаимосвязи между сферами базовых категорий финансов зеленой экономики (рис. 1).

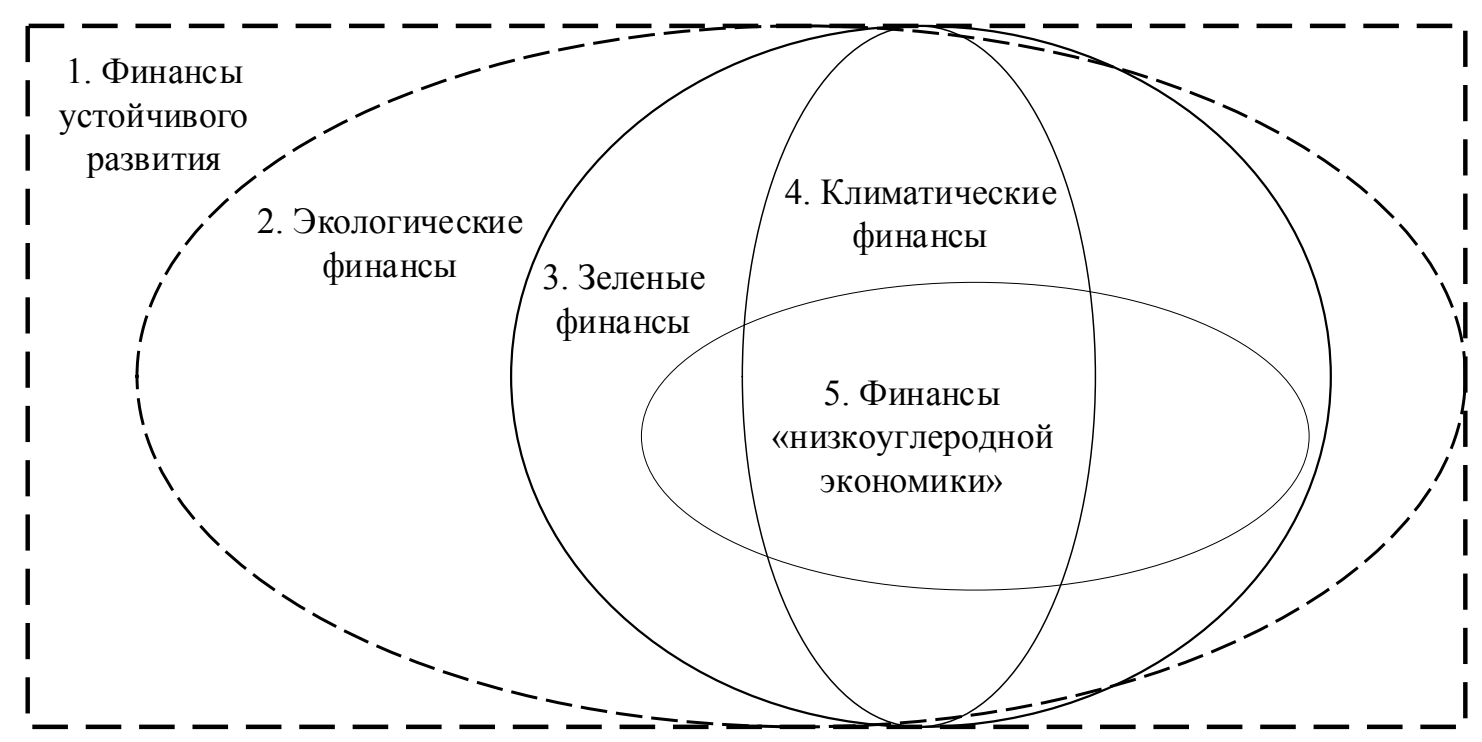

Рис. 1. Взаимосвязи между сферами базовых категорий финансов зеленой экономики

Fig. 1. Interconnections between the basic finance categories of the green economy

Источник: составлено автором на основе [Noh, 2019]

В табл. 1 показана классификация понятий, вовлеченных в экономические отношения, связанные с представленными на рис. 1 сферами финансов зеленой экономики.

С момента зарождения рынка зеленых облигаций в 2007 г., зеленые финансы и зеленая экономика прошли огромный путь развития. На этом пути было создано много разных отраслей зеленой экономики и соответствующих им зеленых сегментов финансового рынка.

Доступность альтернативной энергии возрастает с каждым годом в результате технологического прогресса и снижения ее стоимости. Из данных статистического обзора мировой энергетики ВР (2019) мы видим, как акценты мирового потребления энергии смещаются в пользу возобновляемых видов энергии (табл. 2).

В табл. 3 показаны структурные сдвиги в потреблении энергии в мире за последние два отчетных года, которые также свидетельствуют о росте потребления натурального газа и возобновляемых видов энергии с одновременным сокращением потребления нефти, как следствия развития и усиления роли доли зеленой экономики в мире. 
Классификация понятий, используемых для описания экономических отношений в сфере развития зеленой экономики

Classification of concepts used to describe economic relations in the development of a green economy

\begin{tabular}{|c|c|c|c|}
\hline $\begin{array}{l}\text { Наименование } \\
\text { терминологичес- } \\
\text { кого кластера } \\
\end{array}$ & $\begin{array}{c}\text { Ключевые и наиболее } \\
\text { часто встречающиеся } \\
\text { общепринятые понятия }\end{array}$ & $\begin{array}{l}\text { Дополнительные категории, } \\
\text { встречающиеся в некоторых } \\
\text { страновых классификациях }\end{array}$ & $\begin{array}{l}\text { Спорные } \\
\text { понятия }\end{array}$ \\
\hline \multicolumn{4}{|c|}{ 1. СФЕРА УСТОЙЧИВЫХ ФИНАНСОВ } \\
\hline $\begin{array}{l}\text { 1.2.Энергоэф- } \\
\text { фективность }\end{array}$ & $\begin{array}{l}\text { Программы утилизации } \\
\text { теплоотходов. } \\
\text { Промышленная } \\
\text { энергоэффективность. } \\
\text { Когенерация. } \\
\text { Энергосберегающие } \\
\text { технологии и } \\
\text { энергоэффективные } \\
\text { продукты. }\end{array}$ & $\begin{array}{l}\text { Энергоэффективные } \\
\text { продукты. }\end{array}$ & $\begin{array}{l}\text { Энергоэффек- } \\
\text { тивность } \\
\text { использова- } \\
\text { ния } \\
\text { ископаемых } \\
\text { видов } \\
\text { топлива. }\end{array}$ \\
\hline 1.3. Прочее & & $\begin{array}{l}\text { Широкополосный доступ к } \\
\text { интернету. } \\
\text { Системы виртуальной } \\
\text { конференцсвязи и } \\
\text { технической поддержки. } \\
\text { Центры обработки данных и } \\
\text { сервера на базе возобновляемой } \\
\text { энергии (в т. ч. майнинг в } \\
\text { блокчейне). } \\
\text { Низкоуглеродные мобильные } \\
\text { энергетические станции. }\end{array}$ & \\
\hline \multicolumn{4}{|c|}{ 2. СФЕРА ЭКОЛОГИЧЕСКИХ ФИНАНСОВ } \\
\hline $\begin{array}{l}\text { 2.1. Чистая } \\
\text { (зеленая) } \\
\text { энергия }\end{array}$ & $\begin{array}{l}\text { Ветряная энергетика } \\
\text { Геотермальная энергетика } \\
\text { Солнечная энергетика } \\
\text { Гидроэнергетика } \\
\text { Биомасса как источник } \\
\text { энергии }\end{array}$ & $\begin{array}{l}\text { Прочие возобновляемые } \\
\text { источники энергии } \\
\text { Переработка мусора как } \\
\text { источник энергии } \\
\text { Комбинированное } \\
\text { производство тепловой и } \\
\text { электрической энергии } \\
\text { (когенерация) }\end{array}$ & - \\
\hline $\begin{array}{l}\text { 2.2. Контроль за } \\
\text { выбросами } \\
\text { парниковых } \\
\text { газов, не } \\
\text { связанных / } \\
\text { косвенно } \\
\text { связанных с } \\
\text { энергетикой }\end{array}$ & $\begin{array}{l}\text { Сбор и утилизация метана } \\
\text { на угольных шахтах. } \\
\text { Снижение объемов } \\
\text { выброса парниковых газов, } \\
\text { вырабатываемых в } \\
\text { технологических процессах } \\
\text { производства цемента, } \\
\text { химикатов и пр. }\end{array}$ & - & \\
\hline $\begin{array}{l}\text { 2.3. Контроль за } \\
\text { загрязнением } \\
\text { окружающей } \\
\text { среды и } \\
\text { выбросами } \\
\text { мусора }\end{array}$ & $\begin{array}{l}\text { Контроль за загрязнениями } \\
\text { воздуха и воды. } \\
\text { Восстановление почвы и } \\
\text { месторождений после } \\
\text { добычи полезных } \\
\text { ископаемых. Переработка } \\
\text { мусора как источник } \\
\text { энергии. } \\
\text { Компостирование мусора. } \\
\text { Мусороочистительные } \\
\text { сооружения и фильтры. }\end{array}$ & - & $\begin{array}{l}\text { Вопросы } \\
\text { управления } \\
\text { мусорными } \\
\text { полигонами и } \\
\text { свалками }\end{array}$ \\
\hline
\end{tabular}


Окончание табл. 1

\begin{tabular}{|c|c|c|c|}
\hline $\begin{array}{c}\text { Наименование } \\
\text { терминологичес- } \\
\text { кого кластера } \\
\end{array}$ & $\begin{array}{c}\text { Ключевые и наиболее } \\
\text { часто встречающиеся } \\
\text { общепринятые понятия } \\
\end{array}$ & $\begin{array}{c}\text { Дополнительные категории, } \\
\text { встречающиеся в некоторых } \\
\text { страновых классификациях } \\
\end{array}$ & $\begin{array}{l}\text { Спорные } \\
\text { понятия }\end{array}$ \\
\hline 2.4. Вода & $\begin{array}{l}\text { Защита и сбережение } \\
\text { водных ресурсов }\end{array}$ & $\begin{array}{l}\text { Муниципальное, } \\
\text { промышленное и } \\
\text { сельскохозяйственное } \\
\text { водоснабжение. } \\
\text { Улучшенный дренаж воды с } \\
\text { поверхности земли. } \\
\text { Контроль сточных вод для } \\
\text { соблюдения регуляторных } \\
\text { требований. }\end{array}$ & - \\
\hline \multicolumn{4}{|c|}{ 3. СФЕРА ЗЕЛЕНЫХ ФИНАНСОВ } \\
\hline $\begin{array}{l}\text { 3.1. Сельское } \\
\text { хозяйство и } \\
\text { землепользование }\end{array}$ & $\begin{array}{l}\text { Энергосберегающие и } \\
\text { энергоэффективные } \\
\text { технологии. } \\
\text { Использование и контроль } \\
\text { лесонасаждений и зеленых } \\
\text { плантаций. Восстановление } \\
\text { лесных массивов и } \\
\text { устойчивое управление } \\
\text { ими. }\end{array}$ & Охрана сельского хозяйства. & - \\
\hline \multicolumn{4}{|c|}{ 4. СФЕРА КЛИМАТИЧЕСКИХ ФИНАНСОВ } \\
\hline $\begin{array}{l}\text { 4.1. Системы } \\
\text { реагирования и } \\
\text { управления } \\
\text { чрезвычайными } \\
\text { ситуациями и } \\
\text { стихийными } \\
\text { бедствиями }\end{array}$ & - & $\begin{array}{l}\text { Устойчивая к чрезвычайным } \\
\text { климатическим ситуациям } \\
\text { инфраструктура. } \\
\text { Системы раннего } \\
\text { предупреждения } \\
\text { чрезвычайных ситуаций. } \\
\text { Страхование стихийных } \\
\text { бедствий }\end{array}$ & - \\
\hline \multicolumn{4}{|c|}{ 5. СФЕРА ФИНАНСОВ НИЗКОУГЛЕРОДНОЙ ЭКОНОМИКИ } \\
\hline $\begin{array}{l}\text { 5.1. Развитие } \\
\text { "низкоуглерод- } \\
\text { ной" } \\
\text { инфраструктры }\end{array}$ & $\begin{array}{l}\text { Системы передачи, } \\
\text { хранения и } \\
\text { транспортировки } \\
\text { возобновляемой энергии. } \\
\text { Внедрение систем } \\
\text { генерации и распределения } \\
\text { энергии по технологиям } \\
\text { «smart grid» и «mini grid». }\end{array}$ & - & - \\
\hline 5.2. Транспорт & $\begin{array}{l}\text { Развитие доступной } \\
\text { городской общественной } \\
\text { транспортной } \\
\text { инфраструктуры. } \\
\text { Электрификация железных } \\
\text { дорог. }\end{array}$ & $\begin{array}{l}\text { Электромобили. Гибридные } \\
\text { виды транспорта, } \\
\text { Велосипедные виды } \\
\text { транспорта. } \\
\text { Улучшение логистики и } \\
\text { транспортной доступности. } \\
\text { Виды транспорта на } \\
\text { альтернативных } \\
\text { небензиновых видах топлива. } \\
\text { Развитие пешей доступности } \\
\text { инфраструктуры. }\end{array}$ & $\begin{array}{l}\text { Дизельные } \\
\text { виды } \\
\text { железнодо- } \\
\text { рожного } \\
\text { транспорта. } \\
\text { Железные } \\
\text { дороги для } \\
\text { перевозок } \\
\text { ископаемых } \\
\text { видов } \\
\text { топлива. } \\
\end{array}$ \\
\hline
\end{tabular}

Источник: составлено автором на основе [Официальный сайт ООН, 2020; Purkayastha, 2019]. 
Динамика (темпы роста) потребления различных видов энергии за период 2017-2018 гг. Расчеты основаны на натуральных показателях (млн тонн в отчете ВР)

Dynamics (growth rate) of consumption of various types of energy for the period 2017-2018.

Calculations are based on natural indicators (million tons in BP report)

\begin{tabular}{|c|c|c|c|c|c|c|c|}
\hline $\begin{array}{l}\text { Наименование } \\
\text { региона/страны }\end{array}$ & Нефть & $\begin{array}{l}\text { Нат. } \\
\text { газ }\end{array}$ & Уголь & $\begin{array}{c}\text { Ядерная } \\
\text { энергия }\end{array}$ & $\begin{array}{c}\text { Гидро- } \\
\text { энергетика }\end{array}$ & $\begin{array}{c}\text { Возобновл. } \\
\text { энергия }\end{array}$ & $\begin{array}{l}2017- \\
2018\end{array}$ \\
\hline Северная A & $1,45 \%$ & $9,28 \%$ & $-5,96 \%$ & $0,48 \%$ & $-2,32 \%$ & $9,65 \%$ & $2,78 \%$ \\
\hline $\begin{array}{l}\text { Южная и } \\
\text { центральная }\end{array}$ & & & & & & & \\
\hline Америка & $-0,60 \%$ & $-2,46 \%$ & $3,66 \%$ & $3,10 \%$ & $1,51 \%$ & $12,16 \%$ & $0,31 \%$ \\
\hline Европа & $-0,56 \%$ & $-2,05 \%$ & $-2,67 \%$ & $0,15 \%$ & $9,78 \%$ & $6,13 \%$ & $0,03 \%$ \\
\hline Страны СНГ & $1,26 \%$ & $5,73 \%$ & $6,69 \%$ & $0,39 \%$ & $1,95 \%$ & $24,00 \%$ & $4,41 \%$ \\
\hline Средний вост & $-0,11 \%$ & $4,95 \%$ & $-2,67 \%$ & $-1,04 \%$ & $-26,93 \%$ & $34,24 \%$ & $2,37 \%$ \\
\hline Африка & $-0,40 \%$ & $6,55 \%$ & $3,90 \%$ & $-29,61 \%$ & $6,63 \%$ & $18,51 \%$ & $2,88 \%$ \\
\hline $\begin{array}{l}\text { Азиатско- } \\
\text { Тихоокеанский } \\
\text { регион }\end{array}$ & $2,67 \%$ & $7,42 \%$ & $2,54 \%$ & $12,10 \%$ & $4,19 \%$ & $25,03 \%$ & $4,14 \%$ \\
\hline Итого мир, в т. ч. & $1,19 \%$ & $5,33 \%$ & $1,44 \%$ & $2,37 \%$ & $3,14 \%$ & $14,49 \%$ & $2,90 \%$ \\
\hline Россия & $0,53 \%$ & $5,43 \%$ & $4,89 \%$ & $0,67 \%$ & $2,64 \%$ & $10,52 \%$ & $3,81 \%$ \\
\hline Доля стран ОЭСР & $0,38 \%$ & $4,88 \%$ & $-3,54 \%$ & $0,60 \%$ & $2,12 \%$ & $8,59 \%$ & $1,47 \%$ \\
\hline Не-ОЭСР & $1,94 \%$ & $5,72 \%$ & $3,02 \%$ & $7,46 \%$ & $3,67 \%$ & $24,15 \%$ & $3,91 \%$ \\
\hline $\begin{array}{l}\text { Европейский } \\
\text { Союз }\end{array}$ & $-0,42 \%$ & $-1,56 \%$ & $-5,05 \%$ & $-0,32 \%$ & $15,70 \%$ & $4,76 \%$ & $-0,21 \%$ \\
\hline
\end{tabular}

Источник: Составлено автором на основе [BP Statistical Review of World Energy, 2019].

Таблица 3

Table 3

Структурные сдвиги в потреблении различных видов энергии в мире в период 2017-2018 гг. Structural shifts in consumption of various types of energy in the world in the period 2017-2018

\begin{tabular}{|c|c|c|c|c|c|c|}
\hline \multirow[b]{2}{*}{$\begin{array}{l}\text { Наименование } \\
\text { региона/страны }\end{array}$} & \multicolumn{6}{|c|}{ Структурные сдвиги 2017-2018 гг. } \\
\hline & Нефть & Нат. газ & Уголь & $\begin{array}{l}\text { Ядерная } \\
\text { энергия }\end{array}$ & $\begin{array}{c}\text { Гидро- } \\
\text { энергетика }\end{array}$ & $\begin{array}{l}\text { Возобн. } \\
\text { энергия }\end{array}$ \\
\hline Северная Америка & $-0,51 \%$ & $1,85 \%$ & $1,13 \%$ & $-0,18 \%$ & $-0,30 \%$ & $0,26 \%$ \\
\hline $\begin{array}{l}\text { Южная и центральная } \\
\text { Америка }\end{array}$ & $-0,41 \%$ & $-0,59 \%$ & $0,17 \%$ & $0,02 \%$ & $0,28 \%$ & $0,53 \%$ \\
\hline Европа & $-0,22 \%$ & $-0,49 \%$ & $-0,42 \%$ & $0,01 \%$ & $0,63 \%$ & $0,48 \%$ \\
\hline Страны СНГ & $-0,65 \%$ & $0,67 \%$ & $0,31 \%$ & $-0,20 \%$ & $-0,14 \%$ & $0,01 \%$ \\
\hline Средний восток & $-1,13 \%$ & $1,29 \%$ & $-0,05 \%$ & $-0,01 \%$ & $-0,15 \%$ & $0,04 \%$ \\
\hline Африка & $-1,36 \%$ & $0,96 \%$ & $0,22 \%$ & $-0,25 \%$ & $0,23 \%$ & $0,21 \%$ \\
\hline $\begin{array}{l}\text { Азиатско-Тихоокеанский } \\
\text { регион }\end{array}$ & $-0,41 \%$ & $0,36 \%$ & $-0,74 \%$ & $0,15 \%$ & $0,00 \%$ & $0,63 \%$ \\
\hline Итого мир, в т.ч. & $-0,57 \%$ & $0,55 \%$ & $-0,39 \%$ & $-0,02 \%$ & $\mathbf{0 , 0 2 \%}$ & $0,41 \%$ \\
\hline Россия & $-0,69 \%$ & $0,83 \%$ & $0,13 \%$ & $-0,20 \%$ & $-0,07 \%$ & $0,00 \%$ \\
\hline Доля стран ОЭСР & $-0,42 \%$ & $0,86 \%$ & $-0,79 \%$ & $-0,07 \%$ & $0,04 \%$ & $0,38 \%$ \\
\hline Не-ОЭСР & $-0,58 \%$ & $0,38 \%$ & $-0,31 \%$ & $0,07 \%$ & $-0,02 \%$ & $0,46 \%$ \\
\hline Европейский Союз & $-0,08 \%$ & $-0,32 \%$ & $-0,67 \%$ & $-0,01 \%$ & $0,64 \%$ & $0,45 \%$ \\
\hline
\end{tabular}

Источник: составлено автором на основе [BP Statistical Review of World Energy, 2019]. 
Несмотря на быстрорастущую долю и роль возобновляемой энергетики в мире ее развитие сдерживается недостаточным финансированием в ряде частей мира. Хуже всех развитие возобновляемой энергетики проходит в России, где потребление нефти замещается ростом доли натурального газа и угля (табл. 3). Рассмотрим проблемы, сдерживающие развитие зеленой экономики более подробно.

\section{Проблемы и сдерживающие факторы развития зеленой экономики}

Различные исследования последних лет посвящены выявлению проблем и причин недостаточности финансирования зеленой экономики и зеленых инвестиционных проектов [Noh, 2010, 2014a, 2014b, 2019; Heinkel, et all, 2001; Kaminker and Stewart, 2012; Gouldson, et all, 2015]. Одним из препятствий является то, что сектор зеленых инвестиций обладает недостаточной инвестиционной привлекательностью. Эта проблема связана с новизной технологий, соответствующими высокими рисками, проблемами с кредитными рисками заемщиков и эмитентов [Kaminker and Stewart, 2012]. В этой связи, роль государства в процессах развития зеленой экономики, зеленых финансов и зеленых финансовых инструментов, инструментов гибридного финансирования и ГЧП, позволяющих снижать финансовые риски и стоимость финансирования для этого сектора, очень важна и высока [Bardhan et al., 2014; Braun, and Hazelroth, 2015, Gouldson et al., 2015; Hall et al., 2016].

В исследовании [Yoshino, Taghizadeh-Hesary, 2017] отмечается, что во многих странах существуют следующие важнейшие проблемы развития зеленой экономики: дефицит экспертизы реализации зеленых инвестиционных проектов; объемы национальных рынков капитала недостаточно большие для финансирования требуемого объема зеленых инвестиций; сектора зеленых финансовых инструментов на рынке капитала испытывают проблемы с ликвидностью; стоимость капитала в стране сравнительна высока; присутствуют административные барьеры и высокие транзакционные издержки для крупных институциональных инвесторов и пр.

Из всех перечисленных ограничений, замедляющих развитие зеленой экономики, следует особенно выделить наиболее значимые - высокие кредитные и политические риски для зеленых инвестиционных проектов. Первое наиболее актуально для малых и средних инвестиционных проектов и неинституциональных эмитентов зеленых долговых инструментов. Политические риски проявляются в том, что будущее неконкурентоспособной и дорогой возобновляемой энергии во многом зависит от воли правительств и от их административного ресурса. Далее мы перейдем к исследованию вопросов финансирования зеленой экономики и особенностей оценки стоимости капитала для зеленых инвестиций.

\section{Стоимость капитала зеленых инвестиционных проектов по сравнению с классическими инвестициями}

Зеленые инвестиционные проекты в основном финансируются из собственных средств участников рынка, которые привержены принципам зеленой экономики, а также из привлеченных источников, в основном через инструменты долгового рынка. Ключевыми источниками долгосрочного финансирования зеленых инвестиционных проектов являются финансовые ресурсы пенсионных фондов, страховых компаний [IRENA, 2020], а к краткосрочным и среднесрочным источникам фондирования главным образом относятся банковские кредиты [Rakić, Mitić, 2012; Yoshino, Taghizadeh-Hesary, 2018].

Учитывая высокий уровень риска, свойственный для развивающегося рынка зеленых инвестиций, банковские классические кредиты являются не самой подходящей формой их финансирования, поскольку при этом все кредитные риски концентрируются в руках одного кредитора, и процентная ставка будет далеко не самой привлекательной. Кроме этого, во многих случаях кредит будет в принципе недоступен для частных зеленых инвестиционных проектов и для компаний без соответствующей репутации.

Вопросы оценки ставки дисконтирования и различные подходы, их сильные и слабые стороны, а также особенности их применения рассмотрены в статье [Дорофеев, 2015]. Зеленые 
финансы и зеленые инвестиции внесли определенную специфику в принципы расчета стоимости капитала [Chava, 2014; Schubert \& Barenbaum, 2019].

Компании, которые придерживаются практики социальной и экологической ответственности, получают экономические выгоды в форме более низкой стоимости капитала благодаря более высокому спросу со стороны инвесторов и более низким рискам [El Ghoul, et al., 2011, 2016]. Более того, в современном мире смещение акцентов с финансов в широком смысле этого понятия на более узкие категории - зеленые финансы и финансы устойчивого развития, дают корпорациям новый способ хеджирования будущих рисков, связанных с экологическими и социальными скандалами. Так, корпорации, производящие большой объем загрязнений окружающей среды, а также выпускающие продукцию и услуги, связанные с вооружениями, ядерными технологиями, табачными изделиями, алкоголем, азартными играми, медицинской продукцией из каннабиса и т. п., сталкиваются с более высокими рисками судебного преследования, систематическими рисками и рисками попадания в черные списки институциональных инвесторов [Hong \& Kacperczyk, 2009]. Дополнительный фактор инвестиционной привлекательности в зеленых инвестициях - деловая репутация социально и экологически ответственной компании [Godfrey, 2005; Boutin-Dufresne \& Savaria P, 2004].

В процессе обзора литературы мы встретили общий подход для оценки стоимости капитала, в котором традиционная модель оценки капитальных активов для зеленых инвестиций может быть модифицирована дополнением специфической зеленой премии к ожидаемой доходности инвестора [Noh, 2019]. При этом автор не указывает то, какова должна быть эта премия, а из описательной части идеи следует, что она должна быть положительной, предоставляя инвестору более высокую доходность от инвестирования в проекты с дополнительной зеленой стоимостью.

На наш взгляд, тезис о положительной премии при инвестировании в зеленые инвестиционные проекты ошибочен и противоречит рыночным реалиям. Судя по данным критической массы эмпирических исследований, в современном мире инвестор, придерживающийся принципов зеленых инвестиций, является скорее филантропом и консерватором, получая меньшую доходность и действуя в соответствии с общемировыми социально-политическими трендами.

\section{Методы расчета стоимости капитала для самофинансирования и смешанной схемы финансирования зеленых инвестиционных проектов}

Расчеты стоимости капитала для проектов в сфере зеленых инвестиций, для оценки корпораций, практикующих корпоративную социальную ответственность и защиту окружающей среды, проводятся с учетом того, что вся область зеленой и социальноответственной деятельности сегодня поощряется мировым сообществом и крупными институциональными участниками мирового финансового рынка. Безусловно, в ряде случаев данный факт открывает возможности дешевле привлекать финансовые ресурсы на финансовом рынке под зеленые инвестиционные проекты. Как видоизменится модель оценки стоимости капитала с учетом этой тенденции? На наш взгляд, модель расчета стоимости акционерного капитала, привлекаемого под финансирование зеленых инвестиционных проектов, может быть представлена в виде формулы 1:

$$
\begin{gathered}
r_{g r e e n \_e q u i t y \_c o s t \_o f \_c a p i t a l}=r_{\text {risk-free }}+\beta * r_{\text {historical_equity_market_premium }}+ \\
+r_{S G L O \_p r e m i u m}+r_{g r e e n \_e q u i t y \_p r e m i u m},
\end{gathered}
$$

где $r_{\text {green_equity_cost_of_capital }}$ - стоимость акционерного капитала, рассчитываемая на базе модифицированной модели САРМ; единицы измерения - проценты;

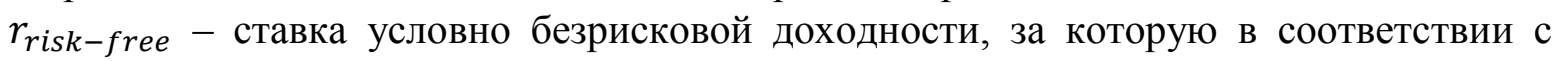
международными практиками обычно принимают доходность десятилетних облигаций США, 
либо доходность облигаций со сроком жизни, сопоставимым оцениваемой зеленой инвестиции, либо ключевую ставку Центрального банка; единицы измерения - проценты;

$\beta$ - коэффициент бета, отражающий рыночный риск инвестиции; представляющий собой коэффициент зависимости между динамикой котировок оцениваемой акции и рыночного индекса в целом; единицы измерения - относительные безразмерные величины;

$r_{\text {historical_equity_market_premium }}-$ долгосрочная историческая премия за риск инвестирования в акции, рассчитываемая как разница между исторической доходностью рынка акций и исторической доходностью рынка облигаций; на практике, как правило, колеблется в диапазоне 4-6 \% годовых в долларах США; единицы измерения - проценты;

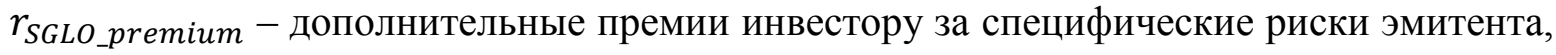
размер и темпы роста корпорации, ликвидность акции и прочее;

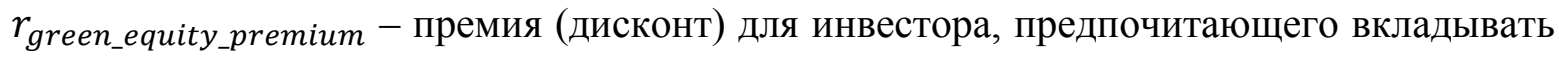
капитал в зеленые акции и развитие зеленой экономики.

Та же самая логика актуальна и для стоимости финансовых ресурсов, привлекаемых на долговом рынке, и соответственно при расчете стоимости долга, направляемого на кредитование зеленых проектов (формула 2):

$r_{\text {green_debt_cost_of_capital }}=r_{\text {risk-free }}+r_{\text {credit_risk_premium }}+r_{\text {green_debt_premium }}$,

где $r_{\text {green_debt_cost_of_capital }}$ - стоимость долга без учета налогового щита, рассчитываемая на базе аддитивной модели, учитывающей кредитные риски и кредитные рейтинги эмитента; единицы измерения - проценты;

$r_{\text {risk-free }}$ - ставка условно безрисковой доходности, за которую в соответствии с международными практиками обычно принимают доходность десятилетних облигаций США, либо доходность облигаций с сроком жизни, сопоставимым оцениваемой зеленой инвестиции, либо ключевую ставку Центрального банка; единицы измерения - проценты;

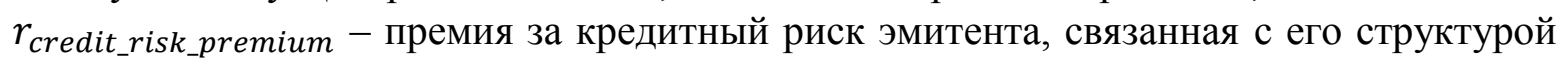
капитала и кредитными рейтингами; единицы измерения - проценты;

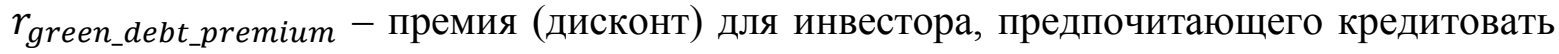
развитие зеленых инвестиций.

Отметим, что формула 2 не скорректирована на налоговый щит $(1-T)$, соответственно, при проведении практических вычислений необходимо учитывать возможный эффект экономии на корпоративном налоге на прибыль, который создает использование долгового финансирования. Данный эффект можно учесть путем умножения стоимости долга до учета налогов на налоговый щит.

И последнее, что мы рассмотрим в методологии, - это модифицированная формула расчета средневзвешенной стоимости капитала, которая необходима для оценки проектов со смешанной формой финансирования (формула 3):

$$
r_{g r e e n \_W A C C}=W d * r_{g r e e n \_d e b t_{-} c o s t_{-} o f_{-} c a p i t a l} *(1-T)+W e * r_{g r e e n_{-} e q u i t y \_c o s t \_o f \_c a p i t a l}
$$

где $r_{\text {green_WACC }}$ - средневзвешенная стоимость капитала, привлекаемого для финансирования зеленых инвестиций; единицы измерения - проценты;

$W_{d}$ - доля долга в структуре капитала; единицы измерения - десятичная дробь;

$W_{e}$ - доля акционерного капитала в структуре капитала; единицы измерения десятичная дробь.

\section{Определение специфической премии (дисконта) для зеленых облигаций}

Дискуссионным вопросом является определение размера специфической премии за финансирование зеленых инвестиций. Получение ответов на этот вопрос представляется более 
легкой задачей для долгового рынка, поскольку информационно-аналитическая база данных Bloomberg позволяет однозначно отфильтровать зеленые облигации от незеленых, кроме этого, на долговом рынке существует строгий контроль за целевым использованием зеленых финансовых ресурсов. Результаты анализа и систематизации ряда эмпирических исследований по вопросу определения премии зеленых облигаций по сравнению с традиционными показали большие противоречия и отсутствие единства мнений по данному вопросу. Премии сильно разнятся в диапазоне от негативной премии в размере -18 базисных пунктов в исследовании [Ehlers and Packer, 2017] до, как это ни парадоксально выглядит в контексте результатов обзора научной литературы, положительной премии в размере $+12,04$ базисных пунктов в исследовании [Bachelet, et all., 2019].

В [Zerbib, 2018] проанализировано 1065 облигаций за период 2013-2017 гг. В своей работе он пишет, что предпочтения зеленых инвесторов сегодня оказывают небольшое, тем не менее, скорее, положительное влияние на цены зеленых облигаций, приводя к возникновению негативной премии к доходности последних в размере около -2,0 базисных пункта по сравнению с их коричневыми аналогами. Автор отмечает, что главными детерминантами более низкой доходности зеленых облигаций являются рейтинги и тип эмитента. Кроме этого, он справедливо подчеркивает важность того, что существование слишком большой негативной премии к доходности зеленых облигаций опасно тем, что может дестимулировать зеленых инвесторов придерживаться своих финансовых стратегий.

Результаты исследований того же периода, но меньшей выборки облигаций в [Bachelet et all., 2019] противоречат идее отрицательной премии за риск для зеленых инвесторов. Авторы пишут про положительную премию за риск к доходности инвесторов в размере $[+2,06$ б. п.; +5,6 б. п.] и разделяют весь рынок зеленых облигаций на институциональный и частный сегменты, показывая, что институционалы на рынке зеленых облигаций, которых было найдено около 35 \% всей выборки, действительно получают преимущества в финансировании, поскольку их облигации торгуются с негативной премией в диапазоне [-1,87 б. п.; -0,9 б. п.] к коричневым аналогам. В то же время, частные зеленые облигации торгуются с премией по доходности в paзмере $[+3,02$ б. п.; +12,04 б. п.] по сравнению с аналогичными коричневым аналогам. Объясняется эта особенность рынка зеленых облигаций тем, что у институциональных инвесторов есть накопленная положительная репутация и своеобразная положительная зеленая кредитная история. В отличие от них частные зеленые инвестиционные проекты и компании нередко нарушают принципы инвестирования, более рискованные и меньше отвечают специфическим требованиям и предпочтениям зеленых инвесторов.

\section{Определение специфической премии (дисконта) для зеленых акций}

Анализ премий для рынка акций и требуемой доходности акционерного капитала требует корректного составления выборки зеленых акций их коричневых аналогов, причем таким образом, чтобы они сохраняли эти характеристики в течение достаточно длительного времени. Дело в том, что в отличие от облигаций акции являются бессрочными финансовыми инструментами, больше подвержены цикличности и учитывают в цене больше факторов, связанных с деятельностью корпорации, чем облигации. Корпорации - не статичные структуры, они постоянно подстраиваются под современные тренды и вызовы. Так, множество нефтедобывающих, производящих алкоголь, табак и прочие формально незеленые продукты компании в 21-м веке все чаще отчитываются о том, как они работают в направлении озеленения своего бизнеса и поиска оптимальных путей соответствия требованиям зеленой и социально ответственной экономики.

Выявление эмитентов, работающих в зеленой экономике и не нарушающих принципы зеленого инвестирования - сложная задача, поскольку почти любая компания косвенно может быть задействована в коричневой экономике и периодически нарушать принципы зеленого инвестирования или социальной ответственности. Кроме этого, в инвестиционной оценке не принято сравнивать корпорации из разных отраслей, т. к. нередко разные сектора и даже отрасли в основном обладают совершенно разными особенностями финансового состояния и 
разными финансовыми метриками. Проведение отраслевого или секторального анализа, к примеру, нефтегазового сектора с сектором здравоохранения, - более простая и выполнимая задача, однако, на наш взгляд, такой подход может привести к критическим погрешностям и искажению результатов исследования.

Наконец, очень дискуссионным является ответ на вопрос, какие именно индикаторы ожидаемой доходности акционера следует использовать. Вероятно, следует выбирать между средней дивидендной доходностью за последние пять лет, форвардным мультипликатором чистой прибыли на акцию к цене акции или пробовать проводить анализ на базе расчета требуемой доходности по вариациям модели оценки капитальных активов САРМ. Во всех перечисленных случаях заведомо будут получены различные значения ставки требуемой доходности (стоимости) акционерного капитала и в этом также заключаются риски искажения результатов [Дорофеев, 2015].

В работе [Reboredo, et all., 2017] авторы проверяли гипотезу о склонности инвесторов платить премию за развитие зеленой экономики. Гипотеза была подтверждена на основании того, что взаимные фонды акций энергетического сектора в период 2010-2016 гг. показывали меньшую инвестиционную привлекательность и более низкую доходность, чем взаимные фонды акций социально ответственных эмитентов, заботящихся о развитии зеленой экономики. На наш взгляд, нельзя считать полученные в работе выводы валидными ввиду вопросов, связанных с выборкой данных для проведения исследования.

Нельзя отрицать тот факт, что нефтегазовый сектор акций США действительно выглядит заметно хуже в росте капитализации по сравнению с широким рынком акций США. Так, с момента эмиссии первой зеленой облигаций в 2007 г. состоялось первое драматическое падение цен на нефть в 21-ом веке, наступил мировой финансовый кризис. В этот момент цены на энергетическом рынке вместе с ценами акций эмитентов нефтегазовой отрасли (XLE или XOP) сильно разошлись с широким рынком акций США (SPY). Проведение графического анализа трендов в ценах данных инструментов производит впечатление, что участники рынка действительно стараются избегать нефтегазовой отрасли и не видят у нее будущего. В 2014 г. после публикации принципов функционирования рынка зеленых облигаций международной ассоциацией участников рынка капиталов (ICMA), произошел второй колоссальный обвал цен на нефтегазовом рынке, заставив ОПЕК принять меры по сокращению предложения нефти на рынке и переведя его на ручное управление. Вместе с тем сфера зеленых финансов получила существенный импульс в развитии.

В результате происходящих изменений за период с 2007 г. по н. в. широкий рынок акций США (SPY) вырос более чем на $130 \%$, а цены на нефть упали более чем на $5 \%$, при этом акции нефтегазового сектора (ХОР) упали более чем на $45 \%$ [Tradingview, 2020]. Анализ текущих финансовых метрик нефтегазовой отрасли по сравнению с отраслями-аналогами, сопоставимыми по уровню долговой нагрузки, показывает следующее:

1. Текущая долларовая дивидендная доходность нефтегазовой отрасли США является самой высокой и составляет 4,25\% [Gurufocus, 2020] при средней доходности отраслейаналогов (деревообрабатывающая промышленность, металлургия, тяжелая промышленность, здравоохранение, персональные услуги и пр.) на уровне 2,46\% и медианной доходности $2,39 \%$. Справочно, ключевая ставка ФРС США на момент исследования находится в диапазоне $1,5 \%-1,75 \%$. Получается, что премия за риск инвестирования в коричневые акции в среднем выше нейтральных акций на 1,8 \% или 180 б. п. Выделить из нейтральных акций зеленые - представляется достаточно сложной задачей, заслуживающей решения в формате проведения самостоятельного исследования.

2. По показателю Е/Р сырьевые отрасли (нефтегазовая, деревообрабатывающая, металлургия) показывают наивысшие доходности и положительные премии к доходности традиционных отраслей рынка акций на уровне 3\%-3,2 \% или 320 б. п.

Таким образом, предварительно мы можем подтвердить гипотезу, что с момента начала развития рынка зеленых облигаций рынок расставил приоритеты не в пользу углеродной 
экономики, однако более точная оценка премий или дисконтов инвестирования в зеленые акции требует дополнительного исследования этой гипотезы.

Отметим, что для табачной отрасли рынка акций США также в среднем характерна премия к ожидаемой доходности в размере $3,15 \%$ по показателю текущей дивидендной доходности акции и 1 \% по показателю ожидаемой акционерной доходности Е/P.

Наконец, для отрасли производителей алкогольных продуктов гипотеза о приоритетности зеленых инвестиций не подтверждается. Акции эмитентов производителей алкогольной продукции торгуются с негативной премией по доходности к отраслям-аналогам по уровню долговой нагрузки. Отрицательная премия составляет $-0,4 \%$ по показателю текущей дивидендной доходности акции и $-1 \%$ по показателю ожидаемой акционерной доходности Е/Р.

Надо сделать оговорку, что полученные результаты представляют собой усредненные предварительные расчеты, т. к. проводились на основе отраслевых данных с анализом текущих, а не исторических значений показателей. Для более точных оценок требуется придерживаться лучших мировых практик оценки акций при расчете премий за риск и захватывать временные периоды от одного до нескольких десятков лет, поскольку в таком случае будут устранены сезонные и циклические колебания акций. Тем не менее полученные предварительные результаты можно использовать как опорную гипотезу в будущих исследования в данном направлении.

\section{Заключение}

Исследование научных публикаций по теме и статистики потребления различных видов энергии в мире показали растущую роль зеленых финансов в мире. Существует очевидный запрос от большого количества стран на изменение парадигмы энергетического баланса мировой экономики. Кроме этого, растет спрос на развитие и повышение объемов и ликвидности зеленого сегмента мирового финансового рынка капитала, в особенности рынка зеленых облигаций. Большая часть исследований отмечают, что эти сегменты финансового рынка на сегодняшний день остаются развивающимися и сравнительно недофинансированными.

Стоимость капитала для финансирования зеленых проектов - дискуссионный вопрос, на который получены разные ответы в разных эмпирических исследованиях. Исследования показывают значительный разброс размеров премий для зеленых облигаций по сравнению с традиционными или так называемыми коричневыми облигациями. Более половины авторов указывают на наличие негативной премии для зеленых облигаций и объясняют это особым статусом зеленого инвестора. Вместе с тем некоторые исследователи объясняют негативную премию тем, что зеленые инвестиции и зеленые принципы выступают новым видом хеджирования бизнес рисков, защищая инвесторов от вероятных будущих судебных преследований, связанных со скандалами в сфере экологии. Кроме этого, в работах исследователей, отмечающих негативную премию, отмечается нетривиальная вероятность ошибок в расчетах, связанных с невысокой ликвидностью рынка зеленых выбранных ими облигаций, и, следовательно, искаженными показателями их доходности.

Рынок облигаций в среднесрочном и долгосрочном периоде эффективен и инвесторами в первую очередь движут классические мотивации риска и доходности, а не флажок зеленой облигации. При всей популярности проблематики зеленого инвестирования мы не нашли достаточно убедительных и однозначных доказательств тому, что зеленые инвесторы действительно «голосуют деньгами» настолько активно, чтобы повлиять на рынки и сделать премии за риск инвестирования в зеленые облигации заметно ниже, чем у классических облигаций с сопоставимыми метриками. Противоречия результатов разных исследований также наводят на идею необходимости верифицировать проведенные результаты исследований в этой области.

Экспресс-анализ долевого рынка также показал определенные противоречия. С одной стороны, очевидны наличие давления и отрицательная динамика цен акций нефтегазового сектора. С 2007 г. интерес инвесторов к классическому энергетическому сектору рынка акций 
США заметно сократился. Анализ доходностей различных секторов рынка акций США показал на начало 2020 г. наличие дополнительной премии за риск в размере 2,4-3,1\% (в зависимости от показателя ожидаемой доходности и методов расчета) для нефтегазового сектора относительно выборки сопоставимых по уровню долга отраслей-аналогов. Для более точной оценки этой премии необходимо проведение дополнительных исследований.

\section{Список литературы}

1. Дорофеев М.Л. 2015. Альтернативная концепция дисконтирования денежных потоков. Финансовая аналитика: проблемы и решения. № 7 (241): 21-36.

2. Информационно-аналитический портал Tradingview. URL: https://www.tradingview.com/x/ N3kiFrde/ (дата обращения 29.01.2020).

3. Информационно-аналитический портал Gurufocus. URL: https://www.gurufocus.com/industry_ overview.php (дата обращения 29.01.2020).

4. Официальный сайт OOH. URL: http://unepinquiry.org/wp-content/uploads/2016/09/1_ Definitions_and_Concepts.pdf (дата обращения 29.01.2020).

5. Официальный отчет BP. Statistical Review of World Energy June 2019. URL: http://www.bp.com/statisticalreview (дата обращения 29.01.2020).

6. Официальный сайт международного агентства по возобновляемой энергетике. International Renewable Energy Agency (IRENA) (2020) URL: https://www.irena.org/publications/2020/Jan/RE-financeGreen-bonds (дата обращения 29.01.2020).

7. Arnell N., Lowe J., Challinor A., Osborn T. 2019. Global and regional impacts of climate change at different levels of global temperature increase. Climatic Change. 155(3): 377-391. DOI: https://doi.org/10.1007/s10584-019-02464-z.

8. Bachelet, M., Becchetti L., \& Manfredonia S. 2019. The Green Bonds Premium Puzzle: The Role of Issuer Characteristics and Third-Party Verification. Sustainability, 11(4), 1098. doi:10.3390/su11041098.

9. Barsky RB, Kilian L. 2004. Oil and the macroeconomy since the 1970s. J Econ Perspect 18(4): $115-134$.

10.Boutin-Dufresne F. \& Savaria P. 2004. Corporate social responsibility and financial risk. Journal of Investing, 13, 57-66.

11.Chava S. 2014. Environmental externalities and cost of capital. Management Science, 60(9), 22232247.

12.Ehlers T., Packer F. 2017. Green bond finance and certification. BIS Quarterly Review. URL: https://ssrn.com/abstract=3042378.

13.El Ghoul S., Guedhami O., Kwok, C., \& Mishra, D. 2011. Does corporate social responsibility affect the cost of capital? Journal of Banking \& Finance, 35, 2388-2406.

14.El Ghoul S., Guedhami O., Kim H., \& Park K. 2016.. Corporate Environmental Responsibility and the Cost of Capital: International Evidence. Journal of Business Ethics, 149(2), 335-361. doi:10.1007/s10551015-3005-6.

15.Eckstein D., Künzel V., Schäfer L., Winges M. 2020. Who Suffers Most from Extreme Weather Events? Weather-Related Loss Events in 2018 and 1999 to 2018. Global climate risk index 2020. Germanwatch E.V. (Available at https://www.germanwatch.org/sites/germanwatch.org/files/20-201e\%20Global\%20Climate\%20Risk\%20Index\%202020_16.pdf).

16.Hamilton JD. 1983. Oil and the macroeconomy since World War II. J Polit Econ 91(2):228-248.

17.Heinkel R., Kraus A. \& Zechner J. 2001. The effect of green investment on corporate behavior. Journal of Financial and Quantitative Analysis, 35, 431-449.

18.Hong H., \& Kacperczyk, M. 2009. The price of sin: The effects of social norms on markets. Journal of Financial Economics, 93, 15-36.

19.Godfrey P. 2005. The relationship between corporate philanthropy and shareholder wealth: A risk management perspective. Academy of Management Review, 30(4), 777-798.

20.Gouldson A, Kerr N, Millward-Hopkins J, Freeman MC, Topi C, Sullivan R. 2015. Innovative financing models for low carbon transitions: exploring the case for revolving funds for domestic energy efficiency programmes. Energy Policy 86:739-748.

21.Kaminker, C. and Stewart, F. 2012. The role of institutional investors in financing clean energy. OECD working papers on finance, insurance and private pensions, no 23. OECD, Paris.

22.Noh H.J. 2019. Financial Strategies to Accelerate Green Growth. In: Sachs J., Woo W., Yoshino N., Taghizadeh-Hesary F. (eds) Handbook of Green Finance. Sustainable Development. Springer, Singapore. 
23.Noh HJ. 2010. Strategies of developing green finance. Korea Capital Market Institute (KCMI), Seoul.

24.Noh HJ. 2014a. Financial strategies to activate green company eco system. KCMI, Seoul.

25.Noh HJ. 2014b. Climate finance. Park Young Sa, Seoul.

26.Purkayastha D. 2019. Managing Credit Risk and Improving Access to Finance in Green Energy Projects. In: Sachs J., Woo W., Yoshino N., Taghizadeh-Hesary F. (eds) Handbook of Green Finance. Sustainable Development. Springer, Singapore.

27.Reboredo, J. C., Quintela, M., \& Otero, L. A. 2017.. Do investors pay a premium for going green? Evidence from alternative energy mutual funds. Renewable and Sustainable Energy Reviews, 73, 512-520. doi:10.1016/j.rser.2017.01.158.

28. Rakić S, Mitić P. 2012. Green banking: green financial products with special emphasis on retail banking products. Educons University, Sremska Kamenica.

29.Schubert W., \& Barenbaum L. 2019.. Issues Involved with Calculating the Cost of Capital in the Not-for-Profit and Public Sectors. Journal of Applied Business and Economics, 21(5). https://doi.org/10.33423/jabe.v21i5.2271.

30.Taghizadeh-Hesary F, Yoshino N. 2015. Macroeconomic effects of oil price fluctuations on emerging and developed economies in a model incorporating monetary variables. Econ Policy Energy Environ 2:51-75.

31.Taghizadeh-Hesary F, Yoshino N. 2016. Monetary policy, oil prices and the real macroeconomic variables: an empirical survey on China, Japan and the United States. China: Int J 14(4):46-69.

32. Taghizadeh-Hesary F, Yoshino N, Abdoli G, Farzinvash A. 2013. An estimation of the impact of oil shocks on crude oil exporting economies and their trade partners. Front Econ China 8:571-591.

33.Taghizadeh-Hesary F, Yoshino N, Mohammadi Hossein Abadi M, Farboudmanesh R. 2016. Response of macro variables of emerging and developed oil importers to oil price movements. J Asia Pac Econ 21(1):91-102. https://doi.org/10.1080/13547860.2015.1057955.

34.Taghizadeh-Hesary F, Yoshino N, Rasoulinezhad E. 2017. Impact of the Fukushima nuclear disaster on the oil-consuming sectors of Japan. J Comp Asian Dev 16(2):113-134. https://doi.org/ 10.1080/15339114.2017.1298457.

35. Yoshino N, Taghizadeh-Hesary F. 2017. Alternatives to bank finance: role of carbon tax and hometown investment trust funds in developing green energy projects in Asia. ADBI working paper 761. Asian Development Bank Institute, Tokyo. Available at: https://www.adb.org/publi cations/alternatives-bankfinance-role-carbon-tax-and-hometowninvestment-trust-funds.

36. Yoshino N, Taghizadeh-Hesary F. 2018. Alternatives to private finance: role of fiscal policy reforms and energy taxation in development of renewable energy project. In: Venkatachalam A, Kaliappa K, Fukunari K (eds) Financing for low-carbon energy transition. Unlocking the potential of private capital. Springer, Singapore, pp 335-358.

37.Zerbib O. 2018. The effect of pro-environmental preferences on bond prices: Evidence from green bonds, Journal of Banking and Finance, doi: https://doi.org/10.1016/j.jbankPn.2018.10.012.

\section{References}

1. Dorofeev M.L. 2015. Al'ternativnaya koncepciya diskontirovaniya denezhnyh potokov [Alternative cash flow discounting concept]. Finansovaya analitika: problemy i resheniya. 7 (241): 21-36.

2. Informacionno-analiticheskij portal Tradingview [Information and analytical portal Tradingview]. URL: https://www.tradingview.com/x/ N3kiFrde/ (data obrashcheniya 29.01.2020).

3. Informacionno-analiticheskij portal Gurufocus [Information and analytical portal Gurufocus]. URL: https://www.gurufocus.com/industry_overview.php (data obrashcheniya 29.01.2020).

4. Oficial'nyj sajt OON [UN official website]. URL: http://unepinquiry.org/wpcontent/uploads/2016/09/1_Definitions_and_Concepts.pdf (data obrashcheniya 29.01.2020).

5. Statistical Review of World Energy June 2019. URL: http://www.bp.com/statisticalreview (data obrashcheniya 29.01.2020).

6. International Renewable Energy Agency (IRENA) (2020) URL: https://www.irena.org/ publications/2020/Jan/RE-finance-Green-bonds (data obrashcheniya 29.01.2020).

7. Arnell N., Lowe J., Challinor A., Osborn T. 2019. Global and regional impacts of climate change at different levels of global temperature increase. Climatic Change. 155 (3): 377-391. DOI: https://doi.org/10.1007/s10584-019-02464-z.

8. Bachelet, M., Becchetti L., \& Manfredonia S. 2019. The Green Bonds Premium Puzzle: The Role of Issuer Characteristics and Third-Party Verification. Sustainability, 11(4), 1098. doi:10.3390/su11041098. 
9. Barsky RB, Kilian L. 2004. Oil and the macroeconomy since the 1970s. J Econ Perspect 18(4):115-134.

10.Boutin-Dufresne F. \& Savaria P. 2004. Corporate social responsibility and financial risk. Journal of Investing, 13, 57-66.

11. Chava S. 2014. Environmental externalities and cost of capital. Management Science, 60(9), $2223-$ 2247.

12.Ehlers T., Packer F. 2017. Green bond finance and certification. BIS Quarterly Review. URL: https://ssrn.com/abstract=3042378.

13.El Ghoul S., Guedhami O., Kwok, C., \& Mishra, D. 2011. Does corporate social responsibility affect the cost of capital? Journal of Banking \& Finance, 35, 2388-2406.

14.El Ghoul S., Guedhami O., Kim H., \& Park K. 2016. Corporate Environmental Responsibility and the Cost of Capital: International Evidence. Journal of Business Ethics, 149(2), 335-361. doi:10.1007/s10551015-3005-6.

15.Eckstein D., Künzel V., Schäfer L., Winges M. 2020. Who Suffers Most from Extreme Weather Events? Weather-Related Loss Events in 2018 and 1999 to 2018. Global climate risk index 2020. Germanwatch E.V. (Available at https://www.germanwatch.org/sites/germanwatch.org/files/20-201e\%20Global\%20Climate\%20Risk\%20Index\%202020_16.pdf).

16.Hamilton JD 1983. Oil and the macroeconomy since World War II. J Polit Econ 91(2):228-248.

17.Heinkel R., Kraus A. \& Zechner J. 2001. The effect of green investment on corporate behavior. Journal of Financial and Quantitative Analysis, 35, 431-449.

18.Hong H., \& Kacperczyk M. 2009. The price of sin: The effects of social norms on markets. Journal of Financial Economics, 93, 15-36.

19.Godfrey P. 2005. The relationship between corporate philanthropy and shareholder wealth: A risk management perspective. Academy of Management Review, 30(4), 777-798.

20.Gouldson A, Kerr N, Millward-Hopkins J, Freeman MC, Topi C, Sullivan R. 2015. Innovative financing models for low carbon transitions: exploring the case for revolving funds for domestic energy efficiency programmes. Energy Policy 86:739-748.

21.Kaminker, C. and Stewart, F. 2012. The role of institutional investors in financing clean energy. OECD working papers on finance, insurance and private pensions, no 23. OECD, Paris.

22.Noh H.J. 2019. Financial Strategies to Accelerate Green Growth. In: Sachs J., Woo W., Yoshino N., Taghizadeh-Hesary F. (eds) Handbook of Green Finance. Sustainable Development. Springer, Singapore.

23.Noh HJ 2010. Strategies of developing green finance. Korea Capital Market Institute (KCMI), Seoul.

24.Noh HJ. 2014a. Financial strategies to activate green company eco system. KCMI, Seoul.

25.Noh HJ. 2014b. Climate finance. Park Young Sa, Seoul.

26.Purkayastha D. 2019. Managing Credit Risk and Improving Access to Finance in Green Energy Projects. In: Sachs J., Woo W., Yoshino N., Taghizadeh-Hesary F. (eds) Handbook of Green Finance. Sustainable Development. Springer, Singapore.

27.Reboredo J.C., Quintela M., \& Otero L.A. 2017. Do investors pay a premium for going green? Evidence from alternative energy mutual funds. Renewable and Sustainable Energy Reviews, 73, 512-520. doi:10.1016/j.rser.2017.01.158.

28.Rakić S, Mitić P. 2012. Green banking: green financial products with special emphasis on retail banking products. Educons University, Sremska Kamenica.

29.Schubert W., \& Barenbaum L. 2019. Issues Involved with Calculating the Cost of Capital in the Not-for-Profit and Public Sectors. Journal of Applied Business and Economics, 21(5). https://doi.org/10.33423/jabe.v21i5.2271.

30.Taghizadeh-Hesary F, Yoshino N. 2015. Macroeconomic effects of oil price fluctuations on emerging and developed economies in a model incorporating monetary variables. Econ Policy Energy Environ 2:51-75.

31.Taghizadeh-Hesary F, Yoshino N. 2016. Monetary policy, oil prices and the real macroeconomic variables: an empirical survey on China, Japan and the United States. China: Int J 14(4):46-69.

32.Taghizadeh-Hesary F, Yoshino N, Abdoli G, Farzinvash A. 2013. An estimation of the impact of oil shocks on crude oil exporting economies and their trade partners. Front Econ China 8:571-591.

33.Taghizadeh-Hesary F, Yoshino N, Mohammadi Hossein Abadi M, Farboudmanesh R. 2016. Response of macro variables of emerging and developed oil importers to oil price movements. J Asia Pac Econ 21(1):91-102. https://doi.org/10.1080/13547860.2015.1057955. 
34.Taghizadeh-Hesary F, Yoshino N, Rasoulinezhad E. 2017. Impact of the Fukushima nuclear disaster on the oil-consuming sectors of Japan. J Comp Asian Dev 16(2): 113-134. https://doi.org/10.1080/15339114.2017.1298457.

35. Yoshino N, Taghizadeh-Hesary F. 2017. Alternatives to bank finance: role of carbon tax and hometown investment trust funds in developing green energy projects in Asia. ADBI working paper 761. Asian Development Bank Institute, Tokyo. Available at: https://www.adb.org/publi cations/alternatives-bankfinance-role-carbon-tax-and-hometowninvestment-trust-funds.

36. Yoshino N, Taghizadeh-Hesary F. 2018. Alternatives to private finance: role of fiscal policy reforms and energy taxation in development of renewable energy project. In: Venkatachalam A, Kaliappa K, Fukunari K (eds) Financing for low-carbon energy transition. Unlocking the potential of private capital. Springer, Singapore, pp 335-358.

37.Zerbib O. 2018. The effect of pro-environmental preferences on bond prices: Evidence from green bonds, Journal of Banking and Finance, doi: https://doi.org/10.1016/j.jbankPn.2018.10.012.

\section{Ссылка для цитирования статьи For citation}

Дорофеев М.Л. 2020. Особенности расчета стоимости капитала в концепции зеленых финансов и зеленых инвестиций. Экономика. Информатика. 47 (2): 338-353. DOI: 10.18413/2687-0932-2020-472-338-353.

Dorofeev M.L. 2020. Cost of capital calculation features in the concept of green finance and green investments. Economics. Information technologies. 47 (2): 338-353 (in Russian). DOI: 10.18413/2687-09322020-47-2-338-353. 